\title{
Teaching Residents How to Effectively Prescribe Nicotine Replacement Therapy on the Clinical Teaching Unit
}

Shannon Riley, Nicole Sitzer, Sophie Corriveau, Gregory Pond, Yayoi Goto, Jill Rudkowski

\begin{abstract}
About the Authors:
Shannon Riley is currently a Respirology PGY5 Resident at the University of Toronto. Nicole Sitzer recently completed an Interstitial Lung Disease Fellowship at the University of Toronto and is a community respirologist. Sophie Corriveau is with the Department of Respirology, McMaster University, Hamilton, Ontario. Gregory Pond is with the Department of Oncology, McMaster University, Hamilton, Ontario. Yayoi Goto is with Clinical Informatics at St. Joseph's Healthcare, Hamilton, Ontario. Jill Rudkowski is with the Department of Medicine, McMaster University, Hamilton, Ontario. Corresponding Author: rudkowj@mcmaster.ca

Submitted: January 31, 2018. Accepted: June 10, 2018. Published: November 9, 2018. DOI: 10.22374/cjgim.v13i4.271
\end{abstract}

\begin{abstract}
Cigarette smoking is the leading cause of preventable death. On the Clinical Teaching Unit, medical students and residents are well positioned to provide smoking cessation resources to patients with the aim of improving quit rates. However, there is a paucity of data evaluating their role in counselling patients on smoking cessation. A survey at our centre identified that medical trainees had a lack of knowledge regarding Nicotine Replacement Therapy (NRT) as a barrier to smoking cessation counselling. We hypothesized that a teaching session on NRT during an inpatient Internal Medicine rotation would increase learner comfort in prescribing these products.

Medical trainees on the Internal Medicine Clinical Teaching Unit (CTU) attended a teaching session during week 4 of an 8-week rotation. Pharmacy records from the 8-week period were retrospectively analyzed to determine NRT prescribing behaviour. Pre-intervention, 5.8\% $(13 / 225)$ of new admissions received an NRT prescription. Post-intervention, 17\% (31/182) of new admissions received an NRT prescription. Using a Fisher's exact test, the percentage of new admissions that received a prescription was significantly different $(\mathrm{p}<0.001)$ between the pre- and post-intervention time frames.

This data suggests that integrating education on NRT into CTU teaching can significantly alter prescribing behaviour and improve access to NRT for patients who need it.
\end{abstract}

\section{RESUME}

Le tabagisme est la principale cause de décès évitable. Dans l'unité d'enseignement clinique, les étudiants en médecine et les résidents sont bien placés pour fournir aux patients des ressources sur le renoncement au tabac dans le but d'améliorer les taux de renoncement au tabac. Cependant, il existe peu de données évaluant leur rôle dans le conseil aux patients en matière de renoncement au tabac. Une enquête menée dans notre centre a révélé que les stagiaires en médecine manquaient de connaissances sur la thérapie de remplacement de la nicotine (TRN) en tant qu'obstacle aux conseils en matière de renoncement au tabac. Nous avons émis l'hypothèse 
qu'une session d'enseignement sur la TRN au cours d'une rotation en médecine interne pour patients hospitalisés augmenterait le confort du stagiaire lors de la prescription de ces produits.

Les stagiaires en médecine de l'unité d'enseignement clinique en médecine interne (UTC) ont assisté à une session d'enseignement au cours de la semaine 4 d'une rotation de 8 semaines. Les dossiers de pharmacie de la période de 8 semaines ont été analysés rétrospectivement pour déterminer le comportement de prescription des TRN. Avant l'intervention, 5,8\% (13/225) des nouvelles admissions ont reçu une ordonnance de TRN. Après l'intervention, 17\% (31/182) des nouvelles admissions ont reçu une ordonnance de TRN. En utilisant un test exact de Fisher, le pourcentage de nouvelles admissions ayant reçu une ordonnance était significativement différent $(\mathrm{p}<0,001)$ entre les périodes de temps pré et post-intervention.

Ces données suggèrent que l'intégration de l'éducation sur les TRN dans l'enseignement de la CTU peut modifier considérablement le comportement de prescription et améliorer l'accès aux TRN pour les patients qui en ont besoin.

A causal relationship has been established between smoking and several disease states, including lung cancer, cardiovascular disease, type 2 diabetes, and rheumatoid arthritis. ${ }^{1}$ Tobacco smoking is the most important risk factor for developing Chronic Obstructive Pulmonary Disease (COPD) by causing an accelerated decline in forced expiratory volume in one second (FEV1). ${ }^{2}$ Currently, over $17 \%$ of Canadian adults smoke either daily or occasionally. ${ }^{3}$ The risk of developing COPD falls by approximately half with smoking cessation. Furthermore, with sustained abstinence from smoking, the rate of decline of pulmonary function among former smokers returns to that of never smokers. ${ }^{4,5}$ There is additional evidence that smoking cessation reduces cancer risk and decreases the risk of mortality from vascular diseases including coronary artery disease. ${ }^{6,7}$ There is also a substantial economic benefit associated with successful smoking cessation. Despite these advantages, it often takes several attempts for patients to quit smoking.

On the Clinical Teaching Unit (CTU), trainees have an opportune time to provide smoking cessation material to patients. At our centre, a survey was distributed to medical learners, primarily to help elucidate potential barriers to smoking cessation interventions. This survey identified a lack of knowledge regarding Nicotine Replacement Therapy (NRT) as a barrier to smoking cessation counselling by the medical learners.

\section{Study Rationale}

Smoking cessation is associated with a mortality and economic benefit; however, many medical schools do not have a formal curriculum at the undergraduate or postgraduate level on smoking cessation counselling. While residents and medical students play a pivotal role in the care of Internal Medicine inpatients, there is a paucity of data evaluating their role in counselling patients on smoking cessation. ${ }^{7}$
Despite evidence that smoking cessation is best achieved through the combination of counselling and pharmacotherapy, residents perceive many barriers to providing this standard of care. In our recently distributed survey at McMaster University, 53\% (19/36) of learners rotating through General Internal Medicine identified a lack of knowledge regarding NRT as a common barrier to smoking cessation counselling. We hypothesized that a teaching intervention promoting the role of NRT in smoking cessation would bridge an identified gap in medical education and promote health advocacy among learners on the CTU. Our teaching intervention aimed to provide the knowledge and resources necessary to increase learner awareness and comfort in prescribing NRT and hopefully facilitate this behaviour change.

\section{Methods}

A 25-minute teaching session was developed to present to learners on the CTU at a McMaster teaching hospital. This centre did not have a nurse-driven NRT prescription protocol or electronic prescription reminders during the study period. The session emphasized the importance of promoting smoking cessation to patients on the CTU as well as the impact of pharmacotherapy as an adjunct to smoking cessation counselling. Prescribing guidelines for NRT and current evidence-based recommendations for smoking cessation pharmacotherapy were included.

Trained senior residents presented this information during a mandatory scheduled teaching session for all learners (residents and medical students) on the CTU during week 4 of an 8 -week rotation.

Electronic pharmacy records were retrospectively extracted from the hospital database to determine NRT prescribing behaviour for patients admitted to Internal Medicine teaching teams. The search strategy was to identify prescriptions for all patients under a given Most Responsible Physician during the 
specified time frame. This allowed for identification of patients admitted to Internal Medicine teaching teams only. The vast majority of admissions to Internal Medicine teaching teams at our centre involve the clinical clerk and/or resident writing the admission orders. We therefore made the assumption that most, if not all, admission prescriptions for these patients are either written directly by a resident, or by a clinical clerk, in which case, the resident would be co-signing the order. The amount and type of NRT prescribed during the 4-weeks pre-intervention was used to establish a control rate for current teaching team patients. After the teaching intervention, another 4 weeks of pharmacy electronic records were obtained to reassess if this intervention had an impact on the amount and type of NRT prescribed to a similar cohort of patients.

Data was also collected on the number of new admissions and current admissions under Internal Medicine teaching teams during this 8-week period. The amount of NRT prescribed was then adjusted for patient volumes.

A chart audit was performed on 100 patients was undertaken to understand the rate of active smoking of the Internal Medicine teaching team patients during this time frame.

\section{Results}

Of the 225 new patient admissions during the pre-intervention time frame, $13(5.8 \%)$ received a nicotine replacement prescription. Conversely, there were 182 new patient admissions during the post-intervention time frame, and 31(17.0\%) received a nicotine replacement prescription during the post-intervention period. Using a Fisher's exact test, the percentage of new patients who received a prescription was significantly different ( $p$ value $<0.001$ ) between the pre- and post-intervention time frames (Table 1).
The chart audit of 100 patients revealed that 23 were documented as active smokers, 70 as previous or non-smokers, and smoking status was unknown for 7 patients.

Table 1 demonstrates a comparison between the type and amount of NRT prescribed on the CTU at St. Joseph's Hospital during a 4-week period before and after a teaching session intervention. The absolute amount of NRT prescribed is also adjusted for CTU patient flow during this time period.

Prior to the teaching session, 15 nicotine replacement prescriptions were prescribed to 13 patients. The median duration of prescriptions was 3 (range 1 to 21 ) days, and 12 (80\%) of the prescriptions were for the $21 \mathrm{mg}$ patch. Following the teaching session, 36 prescriptions were provided to 31 patients. The median duration of prescriptions was 3.5 (range 1 to 38 ) days, and 17 (47.2\%) of the scripts were for the $21 \mathrm{mg}$ patch (see Table 1).

The type of NRT prescription was also statistically different using an exact $\chi^{2}$ test $(p$ value $=0.016)$. Further, since only one patient received a cartridge, and only one received a $7 \mathrm{mg}$ patch, a secondary analysis was performed comparing the prescription of a $21 \mathrm{mg}$ patch versus a $14 \mathrm{mg}$ patch. A Fisher's exact test was performed and the results were statistically significant $(p=0.024)$, demonstrating increased variability in these prescriptions for NRT post-intervention.

A Wilcoxon rank sum test was performed to test if the duration of each prescription was different between the pre- and post-intervention phases; no statistically significant difference was observed $(p=0.62)$.

\section{Discussion}

Providing an innovative strategy to teach smoking cessation to learners on an inpatient rotation at a teaching hospital has demonstrated improved rates of NRT prescribing for active

Table 1. Descriptive Statistics

\begin{tabular}{|c|c|c|c|c|}
\hline \multicolumn{2}{|l|}{ Characteristic } & $\begin{array}{l}\text { Pre-teaching } \\
\text { Intervention }\end{array}$ & $\begin{array}{l}\text { Post-teaching } \\
\text { Intervention }\end{array}$ & p Value \\
\hline Number of Scripts & $\mathrm{N}$ & 15 & 36 & \\
\hline Number of Patients & $\mathrm{N}$ & 13 & 31 & \\
\hline \multicolumn{2}{|c|}{ Percentage of New Admissions } & $5.8 \%$ & $17.0 \%$ & $<0.001$ \\
\hline \multicolumn{2}{|c|}{ Percentage of All Admissions } & $4.0 \%$ & $11.2 \%$ & $<0.001$ \\
\hline Number of MRPs & & 7 & 10 & \\
\hline Duration of Prescription & Median (range) & $3(1-21)$ & $3.5(1-38)$ & 0.62 \\
\hline Type of Prescription & $\begin{array}{l}\text { Cartridge } 10 \mathrm{mg} \\
\text { Patch } 7 \mathrm{mg} \\
\text { Patch } 14 \mathrm{mg} \\
\text { Patch } 21 \mathrm{mg}\end{array}$ & $\begin{array}{c}1(6.7) \\
0(0.0) \\
2(13.3) \\
12(80.0)\end{array}$ & $\begin{array}{c}0(0.0) \\
1(2.8) \\
18(50.0) \\
17(47.2)\end{array}$ & 0.016 \\
\hline
\end{tabular}


smokers. Statistically significant differences were observed between the pre- and post-intervention time periods in terms of both the percentage of patients who received a prescription as well as the type of NRT prescription. Educating learners on the delivery of effective smoking cessation counselling may help target previously identified barriers.

The purpose of NRT is to replace the nicotine from cigarettes to both reduce withdrawal symptoms and the motivation to smoke. The ultimate goal is to assist the patient's transition from smoking to abstinence. ${ }^{7}$ Current Canadian best practice guidelines recommend that all hospitals have a system in place to identify current smokers and manage nicotine withdrawal during hospitalization. ${ }^{8}$ Despite this, the study centre did not have such a system and these recommendations have been difficult to sustain when implemented. A multi-faceted approach is required that includes enabling front-line practitioners, such as medical residents, to ensure patients have access to NRT during hospitalization. ${ }^{9}$

This study adjusted for the number of patients admitted to the CTU during the pre and post-intervention time period; however, the relative number of smokers was not captured in the database. The prevalence of smokers in the general population of the study area was estimated at $22.4 \%{ }^{10}$ which is far above the number of patients NRT was prescribed for during the study period. Although possible, it is unlikely that the change in NRT prescription pre- and post-intervention was due solely to a change in the prevalence of smokers admitted. A chart audit undertaken during the study period confirmed that $>23 \%$ of patients admitted were active smokers which is expected based on population data. Future studies should look to find reliable ways to ascertain the prevalence of active smokers among admitted patients. Although limited by a small sample size, this data suggests that integrating formal education on NRT into the residency curriculum can alter resident prescribing behaviour in the short-term and is one way to improve the numbers of hospitalized patients receiving NRT. Sustainability of our educational session on NRT prescribing was not evaluated, however this would be helpful to assess in future studies to determine long-term impact.

\section{Commercial Interests}

None.

\section{Financial Support}

Parveen Wasi Resident Research Grant in Medical Education, McMaster Internal Medicine Program (\$3500).

\section{Ethics Approval}

Hamilton Integrated Research Ethics Board (HiREB).

\section{References}

1. Glantz SA, Johnson KC. The surgeon general report on smoking and health 50 years later: breast cancer and the cost of increasing caution. Cancer Epidemiol Biomark Prevent. 2014;23:37-46.

2. Lokke A, Lange P, Scharling H, Fabricius P, Vestbo J. Developing COPD: a 25 year follow up study of the general population. Thorax 2006;61:935-9.

3. Statistics Canada. Smoking, 2015. Health Fact Sheets. Catalogue no. 82-625X. Ottawa: Minister of Industry; 2017. Available at: http://www.statcan.gc.ca/ pub/82-625-x/2017001/article/14770-eng.htm

4. Vestbo J, Hurd SS, Agusti AG, et al. Global strategy for the diagnosis, management, and prevention of chronic obstructive pulmonary disease: GOLD executive summary. Am J Respir Crit Care Med 2013;187:347-65.

5. Laniado-Laborin R. Smoking and chronic obstructive pulmonary disease (COPD). Parallel epidemics of the 21 century. Int J Environ Res Pub Health 2009;6:209-24.

6. Godtfredsen NS, Holst C, Prescott E, Vestbo J, Osler M. Smoking reduction, smoking cessation, and mortality: a 16-year follow-up of 19,732 men and women from The Copenhagen Centre for Prospective Population Studies. Am J Epidemiol 2002;156:994-1001.

7. Stead LF, Bergson G, Lancaster T. Physician advice for smoking cessation. Cochrane Database Sys Rev 2008:CD000165.

8. CAN-ADAPTT. Canadian Smoking Cessation Clinical Practice Guideline. Toronto, Canada: Canadian Action Network for the Advancement, Dissemination and Adoption of Practice-informed Tobacco Treatment, Centre for Addiction and Mental Health; 2011

9. Faseru B, Turner M, Casey G, et al. Evaluation of a hospital-based tobacco treatment service: outcomes and lessons learned. J Hosp Med 2011;6:211-8.

10. The Ontario Tobacco Research Unit. CCHS Data on Smoking Prevalence and Second-hand Smoke Exposure in Ontario: Provincial and Regional Estimates. Toronto: Author; 2014. Available at: https://otru.org/wp-content/ uploads/2014/06/update_june2014.pdf 